\title{
Comparison of labial and sublingual salivary gland biopsies in the diagnosis of Sjögren's syndrome
}

\author{
Y L Pennec, J P Leroy, J Jouquan, A Lelong, P Katsikis, P Youinou
}

\begin{abstract}
This study was designed to compare labial and sublingual salivary gland biopsies in the diagnosis of Sjögren's syndrome (SS). Fourteen labial and 29 sublingual specimens were considered positive. There was a better correlation between infiltration of the ductal structure and the focus score in the sublingual salivary gland biopsy than in the labial salivary gland biopsy. Use of sublingual salivary gland biopsy as an additional diagnostic tool in SS is therefore suggested.
\end{abstract}

Sjögren's syndrome (SS) is a chronic inflammatory disease. It consists of the triad of keratoconjunctivitis sicca, xerostomia, and connective tissue disease, most commonly being rheumatoid arthritis or systemic lupus erythematosus. The first two criteria are necessary for the diagnosis of primary $\mathrm{SS}^{1-3}$ but this definition leaves criteria for keratoconjunctivitis sicca ${ }^{4}$ and xerostomia ${ }^{5}$ unspecified.

Keratoconjunctivitis sicca is suspected when characteristic corneal and conjunctival staining with rose bengal is present, and confirmed by reduced tear meniscus, tear break up time, and unanaesthetised Schirmer's test. ${ }^{6}$ In constrast, it is not possible on clinical grounds to diagnose xerostomia unequivocally. The main manifestation is dryness of the mouth. Not all patients present this complaint directly, however, and drugs and many conditions (including anxiety and aging) can lead to subjective sensations of dry mouth, making it unacceptable as the sole criterion for the oral component of SS. The need for an objective way to assess xerostomia has led to the introduction of salivary gland biopsy. Potential complications of open biopsy have discouraged the use of parotid and submandibular gland as a diagnostic procedure. Once labial salivary gland biopsy had been agreed upon, ${ }^{7}$ many studies established the basis for its use as a reliable criterion for xerostomia.

Using a semiquantitative inflammatory focus scoring method, similar to that used on parotid and submandibular glands, ${ }^{8}$ Chisholm and Mason graded inflammation in labial salivary gland biopsy specimens from patients with various rheumatological diseases and in specimens obtained at necropsy. ${ }^{9}$ They defined a focus as an aggregate of at least 50 lymphocytes, and found that more than one focus $/ 4 \mathrm{~mm}^{2}$ area of gland was seen only in patients with SS. The grading criteria were then modified to develop a more quantitative focus scoring method. ${ }^{10}$ This ranged from one to 12 foci $/ 4 \mathrm{~mm}^{2}$. Another study grading 86 labial salivary gland biopsy specimens by qualitative criteria found more and larger foci in patients with primary SS than in those with both SS and rheumatoid arthritis. ${ }^{11}$ Thus Daniels et al diagnosed the salivary component of SS as the presence of focal sialadenitis in labial salivary gland biopsy specimens in a series of 100 patients suspected of having SS. ${ }^{5}$

This problem is far from being completely solved, however. In another study of Daniels 58 patients with a focal sialadenitis on the labial salivary gland biopsy had no keratoconjunctivitis sicca or connective tissue disease, whereas 41 patients without a focal sialadenitis did have keratoconjunctivitis sicca or connective tissue disease, or both. ${ }^{12}$ In a recent report signs of focal sialadenitis were found in $73 / 84$ patients, but only 37 patients scored 4 , which is considered diagnostic for SS. ${ }^{13}$

We therefore undertook this prospective study in order to compare labial and sublingual salivary gland biopsies in the diagnosis of SS.

\section{Patients and methods}

PATIENTS

Fifty seven patients suspected of having SS on the basis of subjective symptoms of dry mouth or dry eyes were considered for this study and gave informed consent. The diagnosis of sicca syndrome was established according to previously described criteria, ${ }^{2}$ with the exception of the histopathological criterion. The presence of keratoconjunctivitis sicca was shown by positive fluorescein staining, abnormal break up time, and Schirmer's test. The oral component was reported by whole saliva and parotid saliva flow and history of salivary gland enlargement. During the same session labial and sublingual salivary gland biopsies were performed in all the patients, of whom seven were excluded because of evidence of sarcoidosis $(n=6)$ or amyloidosis $(n=1)$. Altogether, 50 patients (seven men, 43 women) aged 24-78 entered the series. The serum of all patients was examined for rheumatoid factor, antinuclear antibodies, and antibodies to SSA (Ro) and SSB (La).

Three types of objective criteria were considered: three criteria for keratoconjunctivitis sicca (Schirmer's test $<10 \mathrm{~mm} / 5 \mathrm{~min}$, increased staining with fluorescein dye, and break up time $<10$ seconds), three criteria for xerostomia (decreased basal salivary flow $\leqslant 1.5 \mathrm{ml} / 15 \mathrm{~min} /$ gland, decreased stimulated salivary flow $\leqslant 1$ $\mathrm{ml} / 5 \mathrm{~min} /$ gland, and salivary gland hypertrophy), and three criteria for serological abnormalities (rheumatoid factor $\geqslant 1 / 80$, antinuclear antibody 
Table 1: Contribution of labial and sublingual salivary gland biopsies to the diagnosis of Sjögren's syndrome

\begin{tabular}{|c|c|c|c|c|c|}
\hline \multicolumn{2}{|l|}{ Specimen } & \multicolumn{4}{|c|}{ Number of patients } \\
\hline Labial & Sublingual & Definite* & Probable* & Possible* & Total \\
\hline $\begin{array}{l}+ \\
+ \\
- \\
-\end{array}$ & $\begin{array}{l}+ \\
+ \\
+ \\
-\end{array}$ & $\begin{array}{l}9 \\
2 \\
3 \\
0\end{array}$ & $\begin{array}{l}0 \\
0 \\
7 \\
8\end{array}$ & $\begin{array}{r}3 \\
0 \\
7 \\
11\end{array}$ & $\begin{array}{r}12 \\
2 \\
17 \\
19\end{array}$ \\
\hline Total & & 14 & 15 & 21 & 50 \\
\hline Difference $†$ & & NS & $\mathrm{p}<0.01$ & $\mathrm{p}<0.03$ & $\mathrm{p}<0.01$ \\
\hline
\end{tabular}

$+=$ more than 1 focus $/ 4 \mathrm{~mm}^{2}$.

${ }^{*}$ Definite ( $>6$ criteria), probable ( 5 or 6 criteria), possible ( $\leqslant 4$ criteria) Sjögren's syndrome-see text.

tDifference: $\chi^{2}$ test for paired samples between labial and sublingual salivary gland biopsies in the three groups of patients and in the whole group.

titre $\geqslant 1 / 100$, and anti-SSA or anti-SSB antibodies, or both). The patients were then divided into three categories: definite SS (more than six criteria), probable SS (five or six criteria), and possible Sjögren's syndrome (four or less criteria).

\section{BIOPSY TECHNIQUE}

Labial salivary gland biopsy specimens were obtained by Daniel's technique ${ }^{12}$ in areas where the overlying mucosa seemed normal. Biopsy of the sublingual salivary gland was performed through a linear incision between the first premolar and the lateral cutting tooth.

\section{HISTOPATHOLOGICAL STUDY}

Specimens were embedded in paraffin, sections cut through the middle of each gland, and scoring was done as described by others.

SEROLOGICAL TESTS

Rheumatoid factor was measured by the latex fixation test (Biolyon, Dardilly, France) and by a modification of the Rose-Waaler reaction using $\mathrm{Rh}$ negative group $\mathrm{O}$ human red blood cells and rabbit haemolysin (Institut Pasteur Production, Marnes la Coquette, France). Anti-

Table 2: Relation of histopathological findings to age in the 29 patients with definite or probable Sjögren's syndrome

\begin{tabular}{lll}
\hline $\begin{array}{l}\text { Age of } \\
\text { patients } \\
\text { (years) }\end{array}$ & \multicolumn{2}{|l}{ No positive/No tested (\% positive) } \\
\cline { 2 - 3 } & $\begin{array}{l}\text { Labial } \\
\text { salivary gland }\end{array}$ & $\begin{array}{l}\text { Sublingual } \\
\text { salivary gland }\end{array}$ \\
\hline$\geqslant 50$ & $3 / 9(33)$ & $4 / 9(44)$ \\
$51-70$ & $6 / 13(46)$ & $7 / 13(54)$ \\
$\geqslant 71$ & $2 / 7(29)$ & $7 / 7(100)$ \\
\hline
\end{tabular}

The 21 patients with possible Sjögren's syndrome were excluded from this presentation. nuclear antibodies were tested by indirect immunofluorescence with $\mathrm{HEp}_{2}$ cells as substrate, and antibodies to SSA (Ro) and SSB (La) by counterimmunoelectrophoresis and double immunodiffusion.

\section{STATISTICAL ANALYSIS}

Comparisons were made using the $\chi^{2}$ test for paired samples. Sensitivity and specificity were calculated by standard formulas. ${ }^{14}$

\section{Results}

Neither technique produced appreciable morbidity. None of our patients complained of uncomfortable scars. Table 1 presents the contribution of both biopsies to the diagnosis of SS. Specimens considered positive showed more than one focus $/ 4 \mathrm{~mm}^{2}$ : 14 labial and 29 sublingual specimens $(p<0 \cdot 01)$.

When patients with definite or probable SS were considered as the patient group and patients with possible SS as the control group it was possible to calculate the sensitivity and specificity of each biopsy procedure. The sensitivity and specificity were 0.38 and 0.86 for the labial salivary gland biopsy and 0.66 and 0.52 for the sublingual salivary gland biopsy, but 0.72 and 0.52 for the double biopsy. To evaluate the changes in structure of salivary glands related to age our patients were classified into three age groups $(\leqslant 50,51-70$, and $\geqslant 71$ years) and we looked for a relation between age and the histopathological findings in both biopsies. Table 2 shows the correlation of the histopathological findings with the age of the patients. It was undoubtedly closer in the sublingual salivary gland biopsy than in the labial salivary gland biopsy. Ductal structures with infiltrating lymphocytes seem to be specific

Table 3: Number of salivary gland specimens showing ductal structures infiltrated with lymphocytes in the 31 patients with more than one focus $4 \mathrm{~mm}^{2}$ on labial or sublingual salivary gtand biopsy specimens

\begin{tabular}{|c|c|c|c|c|c|}
\hline \multicolumn{2}{|c|}{ Specimen } & \multicolumn{4}{|c|}{ Number of patients } \\
\hline Labial & Sublingual & Definite & Probable & Possible & Total \\
\hline $\begin{array}{l}+ \\
+ \\
- \\
-\end{array}$ & $\begin{array}{l}+ \\
+ \\
+\end{array}$ & $\begin{array}{l}2 \\
2 \\
6 \\
4\end{array}$ & $\begin{array}{l}0 \\
0 \\
2 \\
5\end{array}$ & $\begin{array}{r}0 \\
0 \\
0 \\
10\end{array}$ & $\begin{array}{r}0 \\
2 \\
8 \\
19\end{array}$ \\
\hline Total & & 14 & 7 & 10 & 31 \\
\hline
\end{tabular}

$+/-$ refer to the presence or absence of ductal structures with infiltrating lymphocytes.

The 19 specimens with no focus or only one focus $/ 4 \mathrm{~mm}^{2}$ were excluded from this presentation. 


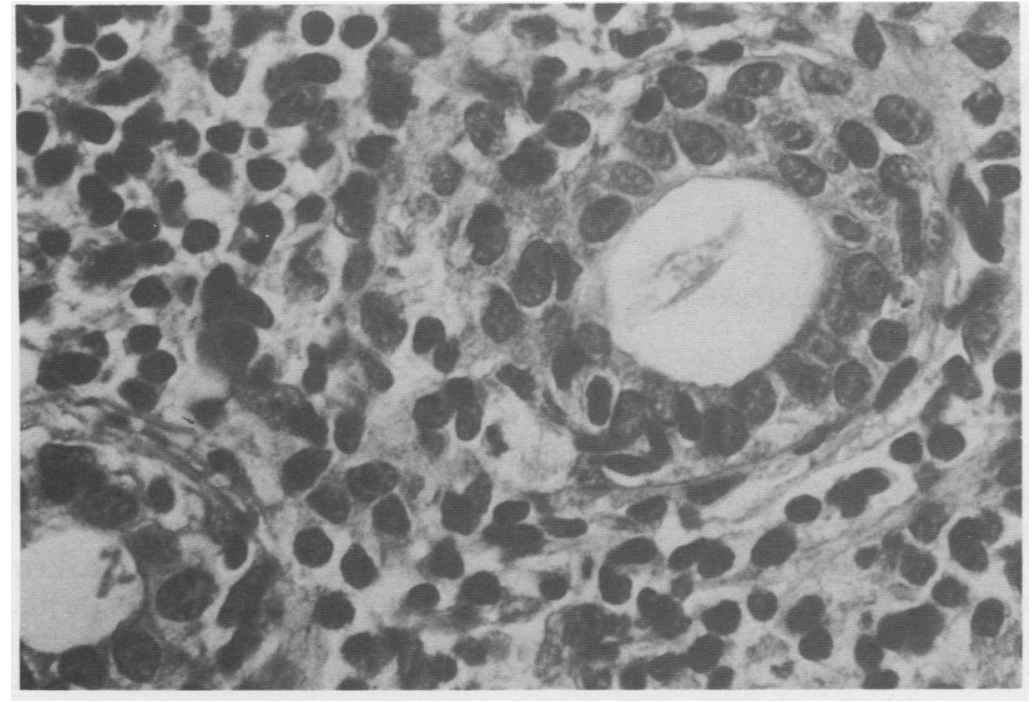

Lymphocyte infiltration of a salivary duct in the sublingual salivary gland biopsy specimen from a patient with Sjögren's syndrome.

for SS (figure). Supposing that the focus score is fairly specific for SS, we then analysed further the 31 patients with more than one focus $/ 4 \mathrm{~mm}^{2}$ on labial or sublingual salivary gland biopsies and compared the incidence of salivary duct infiltration in the two sets of glands. This abnormality was rarely present $(4 / 31,13 \%)$ in labial salivary gland biopsy specimens but found in $10 / 31(32 \%)$ of the sublingual salivary gland biopsy specimens in SS (table 3). Other abnormalities, such as interstitial fibrosis, scattered lymphocytic infiltrates, and dilatation or oncocytosis of the ducts and acini, were found equally by both biopsies.

\section{Discussion}

So far, very few studies have attempted to correlate pathological changes in minor and major salivary glands of patients with SS. Bertram and Hjorting-Hansen reported minor changes in labial salivary gland biopsy specimens in 10 of their 12 patients with parotid gland pathological abnormalities. ${ }^{15}$ Chisholm et al found a general correlation between mild inflammation in the labial salivary glands and in the submandibular glands in 116 unselected subjects at necropsy. ${ }^{16}$ Recently, Wise et al admitted that biopsy of the parotid gland added little information to the routine evaluation as parotid gland abnormalities were never found alone. ${ }^{17}$ Marx et al came to a different conclusion as their study showed a clear superiority of the parotid biopsy over the labial salivary gland biopsy. ${ }^{18}$ In particular they were able to identify specific systemic diseases earlier and with a more obvious histopathology by parotid biopsy than by labial salivary gland biopsy. Our study confirms the diagnostic usefulness of the sublingual salivary gland biopsy in patients suspected of having SS. It can be inferred from the data given in table 1 that 29 specimens from sublingual salivary glands and 14 specimens from labial salivary glands showed more than one focus $/ 4 \mathrm{~mm}^{2}$. Seventeen patients with SS showed a non-convincing pattern on the labial salivary gland biopsy specimens, whereas the pattern on the sublingual salivary gland biopsy specimens was obviously that of SS. The sensitivity is better for the sublingual salivary gland biopsy than for the labial salivary gland biopsy, but the specificity of the latter is better than that of the former. A double biopsy seems to be a sensible compromise.

There is a closer relation in sublingual salivary gland biopsy than in labial salivary gland biopsy between pathological findings and the age of the patients (table 2 ). Our double biopsy procedure may be justified, however, as the oldest patients tend to have the smallest glands. ${ }^{12}$ We would also like to highlight the correlation between infiltration of the ductal structure and the focus score (table 3). This abnormality is found more often in sublingual salivary gland biopsy than in labial salivary gland biopsy. Because it seems to be even more specific for SS than the focus score this is an additional argument for recommending the double biopsy.

We believe that the sublingual salivary gland biopsy is useful in patients suspected of having SS, and suggest its use as an additional diagnostic tool. In view of possible complications histopathologists are reluctant to biopsy sublingual salivary glands. As it is very well tolerated we believe their caution is perhaps unfounded.

1 Youinou P, Pennec Y L. Immunopathological features of primary Sjögren's syndrome. Clin Exp Rheumatol 1987; 5: 173-84.

2 Manthorpe R, Andersen V, Jensen O A, Oxholm P, Prause J U, Schiodt M. Editorial comments to the four sets of criteria for Sjögren's syndrome. Scand F Rheumatol [Suppl] 1986; 61: $31-5$.

3 Moutsopoulos H M, Chused T M, Mann D L, et al. Siögren's syndrome (sicca syndrome): current issues. Ann Intern Med syndrome (sicca synd

4 Mackie I A, Seal D V. The questionably dry eye. $\mathrm{Br} \mathcal{F}$ Ophthalmol 1981; 65: 2-9.

5 Daniels T E, Silverman S Jr, Michalski J P, Greenspan J S, Sylvester R A, Talal N. The oral component of Siögren's syndrome. Oral Surg Oral Med Oral Pathol 1975; 39: 875-85.

6 Schirmer O. Studien zur Physiologie und Pathologie der Tränenabsorderung und Tränenalfulis. Albrecht von Graefes Archiv fur klinische und experimentelle Ophthalmologie 1903; 56: 197-291.

7 Cifarelli P S, Bennett M J, Zaino E C. Siögren's syndrome: a case report with an additional diagnostic aid. Arch Intern Med 1966; 117: 429-31.

8 Waterhouse J P. Focal adenitis in salivary and lacrimal glands. Proceedings of the Royal Society of Medicine 1963; 56: $911-8$.

9 Chisholm D M, Mason D K. Labial salivary gland biopsy in Sjögren's syndrome. $\mathcal{F}$ Clin Pathol 1968; 21: 656-60.

10 Greenspan J S, Daniels T E, Talal N, Sylvester R A. The histopathology of Sjögren's syndrome in labial salivary gland biopsies. Oral Surg Oral Med Oral Pathol 1974; 37: 217-29.

11 Tarpley T M, Anderson L G, White C L. Minor salivary gland involvement in Siögren's syndrome. Oral Surg Oral Med Oral Pathol 1974; 37: 64-74.

12 Daniels T E. Labial salivary gland biopsy in Sjögren's syndrome. Assessment as a diagnostic criterion in 362 syndrome. Assessment as a diagnostic criterion
suspected cases. Arthritis Rheum 1984; 27 : 147-56.

13 Vitali C, Tavoni A, Simi U, et al. Parotid sialography and minor salivary gland biopsy in the diagnosis of Sjogren's syndrome. A comparative study of 84 patients. $\mathcal{F}$ Rheumatol 1988; 15: 262-7.

14 Gallen R S, Gambino S R. Beyond normality. The predictive value and efficiency of medical diagnoses. New York: Wiley, 1975.

15 Bertram U, Hjorting-Hansen E. Punch-biopsy of minor salivary gland in the diagnosis of Sjögren's syndrome. Scand 7 Dent Res 1970; 78: 295-300.

16 Chisholm D M, Waterhouse J P, Mason D K. Lymphocyte sialadenitis in the major and minor glands: a correlation in postmortem subjects. F Clin Pathol 1970; 23: 690-4.

17 Wise C M, Agudelo C A, Semble E L, Stump T E, Woodruff R D. Comparison of parotid and minor salivary gland biopsy specimens in the diagnosis of Siögren's syndrome. biopsy specimens in the diagnosis
Arthritis Rheum 1988; 31: $662-6$.

18 Marx R E, Hartman K S, Rethman K V. A prospective study comparing incisional labial to incisional parotid biopsies in the detection and confirmation of sarcoidosis, Sjogren's disease, sialosis and lymphoma. F Rheumatol 1988; 15: 621-9. 